\title{
Historiadores jaliscienses en la capital. Notas sobre su obra
}

\section{José María Muriá}

(

fenecer el siglo XIX, el proceso centralizador que caracterizó al porfiriato ya había hecho mella en la cultura de la provincia mexicana en beneficio de la capital. Luis Pérez Verdía, en su Historia Particular del Estado de Jalisco, publicada entre 1910 y 1911, reconocía "con tristeza" que Guadalajara ya distaba mucho de ser "aquel centro intelectual que floreció independiente y luminoso en pasadas edades". ${ }^{1}$

Parece evidente que hubo "épocas mejores", como por ejemplo aquélla en que afloró la brillante generación llamada "reformista". Pero tal como afirma el mismo Pérez Verdia, debido a la centralización operada en la ciudad de México en la órbita de los negocios financieros y de la política "... muchos artistas de valía, en pos de fama o de fortuna, emigran a la capital y en ella se establecen". ${ }^{2}$

El daño causado por el porfiriato en este sentido fue muy grave, puesto que Guadalajara había perdido las condiciones que garantizaran un campo suficiente para el desarrollo de sus pensadores y artistas, en tanto que la capital se convertía, a los ojos de éstos, en un prometedor paraiso.

Debe aceptarse que después de la Revolución, si bien fueron abolidos algunos legados porfirianos, esta situación contraria a la provincia tendió a incrementarse en vez de disminuir. A ello contribuyó, sin duda, la intensa emigración de recursos y de gentes que los poseian, en busca de la mayor seguridad que sentian al estar entre un número de habitantes mayor durante los años álgidos de la lucha armada y el compromiso con la propia lucha que adquirieron algunos otros, arrastrados por un torbellino que finalmente los depositaría también en la capital.

Así, cuando se recobró la paz, era menos halagador aún el panorama cultural tapatío y muy pobres las posibilidades de mejorarlo. Además debe recordarse que años después el Estado fue escenario muy destacado de una nueva conflagración que no dejó de agravar más las cosas, con lo cual la "fuga de cerebros" tuvo por fuerza que continuar.

Muchos emigrados ha habido que no se han acordado de sus paisanos más que cuando se ha tratado de recibir algún homenaje por parte de ellos o para concurrir a desempeñar algún puesto público si los avatares políticos así lo han indicado, pero los ha habido también que no han cortado el cordón umbilical y que, aun fuera de casa, siguen interesándose por el conocimiento y la expresión de su tierra.

En el caso de los preocupados por el estudio del pasado, existen los dos tipos. De unos más vale no hacer mención, pero de los otros no puede prescindirse, máxime que han sido ellos quienes, dada su mejor situación para el trabajo - como es la que ofrece la capital-, han aportado los textos que se reconocen, en términos generales, como los más importantes para el saber histórico de Jalisco.

No se pretende aquí ahondar en las razones concretas que los

1 Luis Pérez Verdia, Historia Particular del Estado de Jalisco, t. III, p. 669.

2 Ibid. 
hicieron salir de su solar, ni tampoco mencionarlos a todos. De hecho se pretende tan sólo dejar un testimonio de todos ellos por medio de quienes, según criterio muy particular, son los más representativos.

Por otro lado, no debe pensarse que esta emigración fue un fenómeno que únicamente ocurrió durante las tres o cuatro primeras décadas del siglo y que actualmente las cosas han cambiado. No habria ninguna razón para ello, puesto que la desproporción de posibilidades para la formación y el desarrollo de un historiador, sigue existiendo entre México, D. F. y Guadalajara, Jal.

Entre los que partieron hace más tiempo, por cierto que por razones bien opuestas - a pesar de lo cual nunca perdieron sus fuertes lazos de amistad-, destacan Juan B. Iguínizz y José López Portillo Weber, ${ }^{4}$ dedicados, además, a funciones muy diferentes aun dentro del mismo quehacer historiográfico.

El primero debe considerarse más bien dentro del ámbito de los genealogistas y de los bibliógrafos, entre los cuales desempeñó un destacado papel. Pero en lo que se refiere a Jalisco pudo dar a luz a dos importantes trabajos cuyo principal hincapié se hace en el siglo XIX.

Uno de ellos es un breve texto sobre la Antigua Universidad de Guadalajara, ${ }^{5}$ en el cual, más que en ningún otro, hace gala de un

3 Juan Bautista Iguíniz Vizcaíno nació y murió en Guadalajara, Jal., en 1881 y 1972 Estudió en el Seminario Conciliar de Guadalajara, trasladándose posteriormente a la ciudad de México donde desarrolló actividades como bibliotecario en el Museo Nacional, clasificador y catalogador en la Biblioteca Nacional, bibliotecario del Observatorio Astronómico Nacional, director de la Biblioteca Iberoamericana e investigador de tiempo completo en el Instituto de Investigaciones Históricas de la UNAM. Fue profesor de catalogación, biblioteconomia, clasificación y avalúo de libros, técnica bibliográfica, bibliografia, bibliotecologia, historia del libro e historia de las bibliotecas en la Escuela $\mathrm{Na-}$ cional de Bibliotecarios y Archivistas, en el Colegio de Bibliotecologia y Archivología de la Facultad de Filosofia y Letras, en el Departamento de Bibliotecas de la UNAM, en El Colegio de México y en la Universidad Femenina. Desde 1919 fue miembro de la Academia Mexicana de la Historia, llegando a ser su director en 1968.

Fue muy vasta su obra, que consia de 178 títulos y comprende diversas disciplinas: biblioteconomía, biografía, bibliología, artes gráficas, bibliografia, crítica e historia bibliográfica y relatos y viajes: "La imprenta en México durante la dominación española"; "El libro y la encuadernación"; La imprenta en la Nueva España y las Artes Gráficas en Guadalajara; Los historiadores de Jalisco. Epitome bibliográfico; Bibliografia biográfica mexicana. "La Biblioteca Nacional de México"; Don Luis Pérez Verdia, jurisconsulto e historiador; "Don Genaro Estrada"; "El primer libro impreso en América", en Boletín de la Biblioteca Nacional.

4 José López Portillo y Weber nació en Guadalajara, Jal., en 1889. Padre del presidente de la República con el mismo apellido, hijo del novelista José López Portillo y Rojas, quien fuera gobernador de Jalisco, y nieto de Jesús Lupez Portillo y Serrano, también gobernador del estado, además de prefecto político y comisario imperial durante la intervención francesa.

A los doce años emigró con su familia a la ciudad de México. Realizó estudios de ingenieria en el Colegio Militar y formó parte de la escolta que acompañó al presidente Madero desde Chapultepec al Palacio Nacional en 1913, al iniciarse la "Decena Trágica" y fue artillero voluntario contra los rebeldes de la Ciudadela. Posteriormente, participó activamente en la expropiación petrolera y fue miembro de la Academia Mexicana de la Historia. Además de lo aquí referido, escribió Génesis de los signos de las letras; Dinámica histórica de México; La Gran Tenochtitlán; Historia del petróleo en México y una novela históriça titulada Cristóbal de Oñate. Murió en la ciudad de México en 1975.

3 La antigua Universidad de Guadalajara, de Juan B. Iguíniz, se publicó por vez primera en las Memorias de la Academia Mexicana de la Historia correspondiente de la Real de Madrid (t. III, México, 1944, p. 332-390) y, con algunas adiciones, fue reeditado posteriormente, con el núm. 44 de las Ediciones de Filosofia y Letras de la UNAM, en 1959.

"El Periodismo en Guadalajara 1809-1914. Recopilación de datos históricos, biográficos y bibliográficos" en Anales del Museo Nacional de Arqueología, Historia y Etnografía, 4a. época, t. VII, México, 1932, p. 237-406. 
acendrado catolicismo y de un espíritu firmemente conservador. Sin embargo, por causa de la resistencia de Iguíniz a salirse de la simple presentación de hecho, la información que proporciona es de gran valor puesto que, a la fecha, es muy poco lo que se ha averiguado para ampliar el tema.

En cuanto a la Universidad durante el siglo XIX, después de consumada la independencia, casi no hay más escrito $y$, en cuanto al siglo XVIII - desde que se empezó a insistir en la necesidad de fundarla hasta que se consiguió, o durante sus primeros veinte años de vida -, los pocos trabajos que han aparecido posteriormente, aunque algunos ni siquiera lo citen -como es el de José Luis Razo Zaragoza-, prácticamente plagiaron su obra sin aportar nada nuevo.

Otro importante trabajo de don Juan lo fue El Periodismo en Guadalajara $1809-1915,6$ en el que se hace mención prácticamente de toda la prensa tapatía que había durante ese lapso, con la minuciosidad característica del autor. Esta obra es indispensable para quien estudie el siglo XIX, máxime que sobre el tema tratado tampoco se ha hecho mayor cosa nueva.

Iguíniz sobrepasó los noventa años de vida, de los cuales se mantuvo más de setenta en continua actividad, ${ }^{7}$ sumergido en la Biblioteca Nacional, por lo que su producción fue muy vasta, misma que ya fue enlistada por Ramiro Villaseñor. ${ }^{8}$ En ella se encuentran muchos trabajos más sobre Jalisco de diferentes dimensiones $y$ propósitos: genealogías, bibliografías, reseñas, etc. Entre otras cosas no conviene dejar sin mención una importante recopilación de textos - Guadalajara a través de los tiempos ${ }^{-9}$ escritos durante cuatro siglos por diferentes autores sobre la capital de Jalisco, y otros dos trabajos también imprescindibles para el estudio de nuestro siglo XIX, sobre cuyos temas tampoco se ha averiguado mucho más: Las Artes Gráficas en Guadalajara, publicada en 1943, con motivo de la II Feria Nacional del Libro ${ }^{10}$ y la más añeja de todas las referidas aquí: Los Historiadores de Jalisco..., aparecida en el año de 1918. ${ }^{11}$

En este último libro se hace una relación casi exhaustiva de todos aquéllos que se dedicaron al estudio de Jalisco con anterioridad a la fecha en que se hizo el libro, pero, definitivamente, no abunda prácticamente nada en la motivación de los autores ni en el sentido o la peculiaridad de sus obras, por lo que prácticamente se reduce, como el subtítulo lo indica, a un "Epítome Bibliográfico".

\footnotetext{
${ }^{6}$ Este libro, con pocas modificaciones fue también reeditado con algunas adiciones. $E l$ Periodismo en Guadalajara 1809-1915, Guadalajara, Universidad de Guadalajara, 1955. Biblioteca Jalisciense núm. 13 y 14.

7 Se recomienda ver el Boletín del Instituto de Investigaciones Bibliográficas, de la UNAM, 4 de julio-diciembre de 1970, en "Homenaje a Don B. Iguíniz" en Etcaetera, segunda época, año VI, núm. 22. Guadalajara, octubre-diciembre de 1971, también de homenaje a este autor.

8 Villaseñor y Villaseñor, Ramiro, cfr. "Bibliografia de Juan B. Iguíniz" en Etcaetera, segunda época, año VI, núm. 22. Guadalajara, octubre-diciembre de 1971 p. 23-35 (Número de Homenaje a Juan B. Iguíniz).

9 Juan Iguíniz, (recop.), Guadalajara a través de los tiempos, 2 tomos. Guadalajara, Banco Refaccionario de Jalisco, 1950 y 1951.

10 Juan B. Iguíniz, Las artes gráficas en Guadalajara. Contribución del Edo. de Jalisco a la II Feria Nacional del Libro, México, Talleres Linotipográficos Numancia, 1943.

11 Juan B. Iguiniz, Los Historiadores de Jalisco. Epitome bibliográfico. Obra premiada en el concurso de Bibliografia y Biblioteconomía convocado por la Biblioteca Nacional, México. Imp. de la Secretaría de Hacienda, 1918.
} 
José López Portillo y Weber, originario de una familia de enorme importancia en Jalisco que finalmente se ancló en México a causa de la conmoción revolucionaria, se interesó menos aún en temática que no fuese jalisciense. De hecho lo más importante de su producción versa sobre temas de su estado natal, haciendo su mayor hincapié sobre la primera mitad del siglo XVI, aunque no dejó de hacer una incursión en la "Guerra de Tres años", con su trabajo Jalisco y el Golpe de Estado de Comonfort, ${ }^{12}$ y en la historia del Hospicio Cabañas de Guadalajara. ${ }^{13}$

Pero no hay duda de que sus obras más importantes, más conocidas e imprescindibles son su Conquista de la Nueva Galicia y su Rebelión de la Nueva Galicia'14 (sobre la "Guerra del Mixtón" en 1541), las cuales, a pesar del entusiasmo que despiertan esos temas entre nuestros historiadores, tampoco han podido ser superadas.

Dos décadas después de López Portillo e Iguíniz, fue J. Ignacio Dávila Garibi15 quien decidió dejar el valle de Atemajac para ir en pos de los mejores horizontes del Anáhuac, lo cual privó a Guadalajara y especialmente a su Iglesia de uno de sus principales actores culturales.

La ausencia de Dávila Garibi fue especialmente resentida puesto que, antes de partir, había tenido ya distinguidas actuaciones en el medio local, especialmente en la Junta Auxiliar Jalisciense de la Sociedad Mexicana de Geografía y Estadística.

$\mathrm{Su}$ longevidad le permitió concluir una larga serie de trabajos que van desde desafortunadas incursiones en los temas prehispánicos ${ }^{16} \mathrm{a}$ intervenciones plenas tanto de erudición como de catolicismo en diferentes periodos de nuestra historia. Sin embargo, en cuanto al espacio geográfico, puede asegurarse que Dávila Garibi casi no quitó el dedo del renglón y que la inmensa mayoría de sus títulos son de tema jalisciense.

Ello le ayudó muchísimo a la consumación de su obra más

12 José López Portillo y Weber, "Jalisco y el Golpe de Estado de Comonfort" en La Reforma en Jalisco y el Bajío, Guadalajara, Font, 1959, p. 126-162.

13 José López Portillo y Weber, "Guadalajara, el Hospicio Cabañas y su Fundador" en: ..., Justino Fernández e Ignacio Díaz Morales, El Hospicio Cabañas, México, Jus. 1971 , p. 1-99.

${ }^{14}$ José López Portillo y Weber, La Conquista de la Nueva Galicia, México, Secretaría de Educación Pública, Departamento de Monumentos.

A pesar de la importancia de estos trabajos, nadie se preocupó gran cosa por su reedición cuando se agotaron, hasta que el primogénito de este autor fue postulado como candidato a la Presidencia de la República. De entonces a la fecha ha habido reediciones; pero desafortunadamente se han hecho con la primordial intención de obsequiárselas al Presidente, quien ya los debe de tener, y no para que estén al abasto de los historiadores.

15 José Ignacio Dávila Garibi nació en Guadalajara, Jal., en 1888. Obtuvo la licenciatura en derecho en 1915; en su ciudad natal fungió como secretario perpetuo de la Junta Auxiliar Jalisciense de la Sociedad Mexicana de Geografía y Estadistica y fue profesor de la Escuela Libre de Jurisprudencia. Se trasladó posteriormente a la ciudad de México donde fue profesor de náhuatl, etimologías y raices de lenguas indigenas en la Universidad Nacional Autónoma de México. Se inició en el periodismo en 1902 y 8 años más tarde administró la revista Juventud; también dirigió el Boletín de la Junta Auxiliar Jalisciense de la Sociedad Mexicana de Geografia y Estadística y fue rescopilador y paleógrafo de la revista Colección de documentos históricos inéditos o muy raros referentes al arzobispado de Guadalajara.

Fue miembro de la Academia Mexicana de la Historia y de la Academia Mexicana de Genealogía y Heráldica y doctor honoris causa de la Academia Studiorum Minerva de Bali. Durante muchos años y hasta su muerte, ocurrida en 1981, fue investigador de la Universidad Nacional Autónoma de México. Su vasta bibliografia comprende 55 libros y 300 folletos, todos ellos de tema mexicano y Jalisciense en su mayoría.

${ }^{16}$ V. gr. J. Ignacio Dávila Garibi, Breves apuntes acerca de los chimalhuacanos: civilización y costumbre de los mismos, Guadalajara, ed. del autor, 1927. 
voluminosa, empezada a publicar durante 1957, en la cual recoge buena parte de sus investigaciones anteriores. Se trata de los seis gruesos volúmenes que componen sus Apuntes para la Historia de la Iglesia en Guadalajara, ${ }^{17}$ mismos que comprenden, al igual que la Historia de Jalisco de Pérez Verdía, "desde los primeros tiempos de que se tiene noticia" hasta "el siglo XIX".

Dada la religiosidad pública y privada de que hizo siempre gala Dávila Garibi, obvio es que esta obra contase no sólo con todos los permisos sino también con el respaldo económico para su impresión de quien era a la sazón el mayor jerarca de la Iglesia tapatía de aquel entonces, el primo del autor, José Garibi Rivera, a quien está dedicada además toda esta obra en compañia del arzobispo anterior, Francisco Orozco y Jiménez.

En el año de 1906, otro joven de dieciséis años emigró a la capital, Jesús Amaya Topete, ${ }^{18}$ natural de Ameca, Jal. Pero no obstante la corta edad que tenía al partir, nunca se identificó plenamente con la urbe. Como ha sucedido muchas veces, durante años, pacientemente, fue recogiendo en sus horas libres datos sobre su poblición de origen. Asi, en 1951, apareció su obra más importanle. dmeca, protofundación Mexicana ${ }^{19}$ en la cual se entremezcla la reproducción de documentos de la época estudiada y cuya conceptuación es enormemente inferior a la información, su Hidalgo en Jalisco ${ }^{20}$ y su "estudio biográfico" de Los conquistadores Fernández de Hijar y Bracamonte, de los que se dice descendiente. ${ }^{21}$

Todos estos autores han fallecido ya, pero no debe pensarse que la ciudad de México no se ha enriquecido con la presencia de otros autores más jóvenes. De ellos bastará mencionar uno, sin duda en el primer plano de los historiadores mexicanos actuales, que, desgraciadamente para el conocimiento del pasado de Jalisco, tan sólo una pequeña parte de su vasta producción versa sobre el tema. Se trata de Moisés González Navarro, ${ }^{22}$ investigador de El Colegio de México,

17 J. Ignacio Dávila Garibi, Apuntes para la Historia de la Iglesia en Guadalajara. México, Editorial Cultura, t. primero 1957, t. segundo 1961, t. tercero, Núm. 1 1963, t. tercero Núm. 2 1963, t. cuarto Núm. 11967 y t. cuarto Núm. 21967.

18 Jesús Amaya Topete nació en Ameca, Jal., en 1889 y murió en la ciudad de México en 1976. No obstante ser autodidacta, dedicó su vida al cultivo de la historia, centrando sus obras en los periodos de la conquista e independencia de México. Además de las referidas en el texto, es autor entre otros de los siguientes libros: La madre de Dios: génesis e historia de nuestra Señora de Guadalupe; El padre Hidalgo y los suyos; Atlas mexicano de la conquista.

Amaya Topete desarrolló muchas actividades desde que se trasladó a Guadalajara en 1901, además de estudiar en la Escuela de Comercio. Después de 1906, en la ciudad de México, trabajó en varias empresas mercantiles, desarrollando al mismo tiempo una intensa actividad periodística.

Aprendió varios idiomas, pero los que más empleó fueron el inglés y el esperanto. $\mathrm{El}$ primero para hacer numerosas traducciones que le encargó el Fondo de Cultura Económica, el segundo para escribir sobre temas literarios y filosóficos.

19 Jesús Amaya, Ameca, protofundación Mexicana, México, Lumen, 1951.

20 Jesús Amaya, Hidalgo en Jalisco, ensayo biohistoriográfico, Guadalajara, Sociedad Impulsora de las Letras, 1964.

21 Jesús Amaya, Los conquistadores Fernández de Hijar y Bracamonte, Biogeneográfico, Guadalajara, Gobierno del Estado de Jalisco, 1952.

22 Moisés González Navarro nació en Guadalajara, Jal., en 1926. Obtuvo la licenciatura en derecho en la Universidad Nacional Autónoma de México, cursó la maestría de ciencias sociales en El Colegio de México y efectuó estudiós de posgrado en la Ecole Practique des Hautes Etudes de París. Ha dictado conferencias y participado en coloquios y congresos desde 1949. 
de quien debe mencionarse una recopilación de documentos sobre $E l$ repartimiemo de indios en Nueva Galicia, publicado en $1953,{ }^{2.3}$ un estudio sobre Ignacio L., Vallarta y su ambiente político y jurídico, que data de $1949^{24}$ y un reportaje sobre la situación que envolvia a los historiadores en 1951, titulado Jalisco, la Historia y sus Instrumentos, escrito en colaboración con Miguel de la Mora. ${ }^{25}$

Con posterioridad a estas fechas, por lo menos hasta donde tenemos noticia, el interés de ese autor ha derivado hacia otras latitudes y pro-. blemas.

Otros emigrados hay, más jóvenes aún, que se encuentran dando los primeros pasos con buenos augurios dentro de la investigación histórica, y que salieron de Guadalajara para radicar en la ciudad de México, pero su quehacer es todavía un asunto del futuro y no del pasado.

Ha sido investigador de El Colegio de México, donde ha escrito numerosas criticas y artículos en revistas especializadas, así como diversos libros, entre los que destacan los siguientes: El Pensamiento Político de Lucas Alamán; Vallarta en la Reforma; Estadísticas sociales del Porfiriato; El Porfiriato. La vida social; La colonización en México; Las huelgas tex iles en el Porfiriato; Raza y tierra; La Confederación Nacional Campesina; Anatomía d.l Poder en México, además de los mencionados aquí.

23. Moisés González Navarro, El repartimiento de indios de Nueva Galicia, México, Museo Nacional de Historia (INAH), 1953. Serie Científica núm. 1.

It Moisés González Navarro, Vallarta y su ambicml' polition I juridico, México, Junta Mexicana de Investigaciones Históricas, 1949.

${ }_{25}$ Moisés González Navarro, "Jalisco, la Historia y sus instrumentos" en Historia Mexicana, vol. I. 1 (1) El Colegio de México, julio-septiembre de 1951. p. 149-163. 